\title{
The activation of p38 MAPK limits the abnormal proliferation of vascular smooth muscle cells induced by high sodium concentrations
}

\author{
YAN WU $^{1 *}$, JUAN ZHOU $^{1,2^{*}}$, HUAN WANG $^{1}$, YUE WU $^{1}$, QIYUE GAO $^{1}$, LIJUN WANG ${ }^{1,2}$, QIANG ZHAO $^{1}$, \\ PEINING LIU ${ }^{1}$, SHANSHAN GAO ${ }^{1}$, WEN WEN ${ }^{1}$, WEIPING ZHANG ${ }^{1}$, YAN LIU ${ }^{1}$ and ZUYI YUAN ${ }^{1-3}$ \\ ${ }^{1}$ Department of Cardiovascular Medicine, The First Affiliated Hospital of Xi'an Jiaotong University; \\ ${ }^{2}$ Shaanxi Key Laboratory of Molecular Cardiology; ${ }^{3}$ Key Laboratory of Environment \\ and Genes Related to Diseases, Xi'an Jiaotong University, Xi'an, Shaanxi 710061, P.R. China
}

Received June 27, 2015; Accepted October 23, 2015

DOI: $10.3892 / \mathrm{ijmm} .2015 .2394$

\begin{abstract}
The aim of the present study was to ascertain whether high sodium levels can directly promote the proliferation of vascular smooth muscle cells (VSMCs) and to elucidate the underlying mechanisms. Additional sodium chloride $(\mathrm{NaCl})$ was added to the routine culture medium. Cell proliferation was evaluated by 3-(4,5-dimethylthiazol2-yl)-2,5-diphenyltetrazolium bromide (MTT) assay and 5-ethynyl-2'-deoxyuridine (EdU) incorporation assay. The mRNA expression level of proliferating cell nuclear antigen (PCNA) was measured by reverse transcription-quantitative polymerase chain reaction (RT-qPCR). The protein expression levels of PCNA and phosphorylated c-Jun amino $\mathrm{N}$-terminal kinase (p-JNK), phosphorylated extracellular signal-regulated kinase 1/2 (p-ERK1/2) and phosphorylated p38 mitogen-activated protein kinase (p-p38 MAPK) were measured by western blot analysis. Cell proliferation assay revealed that $\mathrm{Na}^{+}$rather than $\mathrm{Cl}^{-}$or osmotic pressure promoted the proliferation of the VSMCs. The high sodium level upregulated the expression of PCNA and the phosphorylation levels of JNK, ERK1/2 and p38 MAPK. The inhibition of JNK and ERK1/2 decreased PCNA expression. Of note, the inhibition of p38 MAPK using the inhibitor, SB203580, increased PCNA expression. However, when p38 MAPK was activated by anisomycin, PCNA expression was decreased. On the whole, our findings demonstrate that a relatively high sodium level per se directly promotes the proliferation of VSMCs through the
\end{abstract}

Correspondence to: Professor Zuyi Yuan, Department of Cardiovascular Medicine, The First Affiliated Hospital of Xi'an Jiaotong University, 277 West Yanta Road, Xi'an, Shaanxi 710061, P.R. China E-mail: zuyiyuan@mail.xjtu.edu.cn

*Contributed equally

Key words: c-Jun N-terminal kinase, vascular smooth muscle cells, extracellular signal-regulated kinase $1 / 2$, sodium, proliferation, p38 mitogen-activated protein kinase
JNK/ERK1/2/PCNA pathway. At the same time, this induction of the proliferation of VSMCs due to high sodium levels can be maintained at a low level via the activation of p38 MAPK.

\section{Introduction}

As the principal cation in extracellular fluid, sodium $\left(\mathrm{Na}^{+}\right)$is an essential nutrient for the maintenance of normal cell function. However, a high-sodium diet (HSD) has been widely be implicated in the development of hypertension (1-3) and cardiovascular diseases, particularly fatal coronary heart diseases $(1,4)$ and stroke $(1)$.

Under physiological conditions, cells, such as inner medullary collecting duct (IMCD) cells of the collecting duct and vascular smooth muscle cells (VSMCs) of renal capillaries in the renal medulla, are normally exposed to variably high concentrations of urea and sodium chloride $(\mathrm{NaCl})$, as a consequence of the urine concentrating mechanism (5). Under antidiuretic conditions, $\mathrm{NaCl}$ and urea are the most prevalent solutes in the medullary interstitium (6). In vitro studies have reported that when IMCD3 cells are exposed to culture medium to which extreme high concentrations of $\mathrm{NaCl}$ are added, this may lead to DNA damage (212.5 mM NaCl added) (7), oxidative stress (300 mM NaCl added) (8) and cell cycle arrest (100 $\mathrm{mM} \mathrm{NaCl}$ added) (9). Therefore, the mechanisms responsible for the adaptation of cells such as IMCD3 and VSMCs to various concentrations of $\mathrm{Na}^{+}$remain poorly understood and thus warrant further investigations.

Apart from the renal medulla, the interstitium containing large amounts of glycosaminoglycans is considered to be a separately regulated space for $\mathrm{Na}^{+}$homeostasis $(10,11)$. Long-term balance studies on humans have confirmed that considerable amounts of $\mathrm{Na}^{+}$accumulate in the interstitium due to excessive $\mathrm{NaCl}$ consumption (12-14). The skin $\mathrm{Na}^{+}$concentration due to HSD can be as high as 180 to $190 \mathrm{mM}$ in rats (15). The study by Machnik et al further demonstrated that the interstitial accumulation of $\mathrm{Na}^{+}$in skin results in hyperplasia of the lymph capillary network (10). Therefore, apart from physiological conditions in the renal medulla, it is necessary to further address whether HSD can lead to excess $\mathrm{Na}^{+}$accumulation in 
different tissues and whether this $\mathrm{Na}^{+}$retention may be associated with any adverse effects.

It should be noted that salt restriction further improves blood pressure control in patients treated with a combination of an angiotensin-converting enzyme (ACE) inhibitor and a diuretic (16). Matsushita et al also found that the combination of HSD with bilateral oophorectomy significantly increased the body $\mathrm{Na}^{+} /$water ratio, and increased cerebral aneurysm formation irrespective of hypertension (17). The abnormal proliferation of VSMCs is considered responsible for the physiological and pathophysiological changes taking place in the vascular wall $(18,19)$. In this study, we aimed to assess whether $\mathrm{Na}^{+}$per se directly affects the proliferation of VSMCs at relatively higher concentrations and to elucidate the underlying mechanisms. This may firstly shed light on the mechanisms responsible for the adaptation of VSMCs to high concentrations of $\mathrm{Na}^{+}$, and secondly, it may reveal the possible direct pathogenic effect of the excessive consumption of $\mathrm{Na}^{+}$, which is independent of pressure, the renin-angiotensin-aldosterone system (RAAS) $(20,21)$ and endothelial function (22).

\section{Materials and methods}

Reagents, kits and antibodies. Dulbecco's modified Eagle's medium (DMEM)/high glucose and phenol red-free DMEM were purchased from HyClone (Logan, UT, USA). Charcoal stripped fetal bovine serum (FBS) was obtained from Gibco-BRL (Grand Island, NY, USA). Rabbit monoclonal antibodies against proliferating cell nuclear antigen (PCNA; 1:1,000; \#13110), phosphorylated c-Jun amino N-terminal kinases (p-JNK; 1:1,000; \#4668) and phosphorylated extracellular signal-regulated kinase 1/2 (p-ERK1/2; 1:2,000; \#4370) were provided by Cell Signaling Technology (Beverly, MA, USA). Rabbit polyclonal antibody against phosphorylated p38 mitogen-activated protein kinase (p-p38 MAPK) was supplied by Signalway Antibody LLC (College Park, MD, USA). Rabbit monoclonal antibody against $\beta$-actin $(1: 10,000 ;$ JC-PA- $\beta$ A1) and horseradish peroxidaseconjugated goat-anti-rabbit antibody (1:4,000; JC-PC012-1h) were purchased from Geneshare (Xi'an, Shannxi, China). $\mathrm{NaCl}$, choline chloride, sorbital, mouse monoclonal anti-actin, $\alpha$-smooth muscle-FITC antibody (anti- $\alpha-S M$-actin antibody; F3777) and DAPI were obtained from Sigma-Aldrich (St. Louis, MO, USA). The Cell-Light ${ }^{\mathrm{TM}}$ 5-ethynyl-2'-deoxyuridine (EdU) imaging detecting kit was purchased from RiboBio (Guangzhou, China). SP600125 (a JNK inhibitor) was provided by Cell Signaling Technology. PD98059 (an ERK1/2 inhibitor), SB203580 (a p38 MAPK inhibitor) and anisomycin (a p38 MAPK activator) were supplied from Santa Cruz Biotechnology (Dallas, TX, USA). In addition, 3-(4,5-dimethylthiazol-2-yl)-2,5-diphenyltetrazolium bromide (MTT) was purchased from Amresco (Solon, $\mathrm{OH}, \mathrm{USA})$.

Cell culture and treatment. Rat VSMCs were purchased from CHI Scientific, Inc. (Jiangsu, China) and cultured in DMEM supplemented with $10 \% \mathrm{FBS}$ at $37^{\circ} \mathrm{C}$ under $5 \% \mathrm{CO}_{2} / 95 \%$ air in a humidified incubator. Cells at passages 3 to 8 with a purity of $>95 \%$ (determined by immunofluorescence staining for $\alpha$-SMactin) were used in the experiments. In order to obtain quiescent VSMCs, the cells were incubated in serum-free medium for 24 h. Subsequently, standard DMEM supplemented with
5\% FBS was used as the control culture medium, in which the $\mathrm{Na}^{+}$concentration was approximately $156 \mathrm{mM}$. High-sodium medium was prepared by the addition of $\mathrm{NaCl}(10,20,30,40$ and $50 \mathrm{mM}$,respectively; additional to the levels already present in the medium) to the control culture medium. Choline chloride and sorbital were used to examine the effects of chloridion $\left(\mathrm{Cl}^{-}\right)$ and osmotic pressure on the proliferation of the VSMCs. High$\mathrm{Cl}^{-}$medium was prepared by the addition of choline chloride $(10,20,30$, and $50 \mathrm{mM}$, respectively; additional to the levels already present in the medium) to the control culture medium. High-osmotic pressure medium was prepared by the addition of sorbital $(20,40,60,80$ and $100 \mathrm{mM}$, respectively; additional to the levels already present in the medium) to the control culture medium. For MTT assay, the VSMCs were treated for 12, 24 or $48 \mathrm{~h}$. For EdU incorporation assay, the VSMCs were treated for $24 \mathrm{~h}$. PCNA expression at the mRNA level was detected following treatment for 3, 6, 9 and $12 \mathrm{~h}$. PCNA expression at the protein level was detected following treatment for 6,15 , or 24 h. Phosphorylation levels were detected after 15, 30, 60, 90 and $120 \mathrm{~min}$ of intervention. To examine the effects of 3 MAPK members on the proliferation of VSMCs induced by additional $\mathrm{NaCl}$, the cells were pre-treated wtih SP600125 (a JNK inhibitor), PD98059 (an ERK1/2 inhibitor), SB203580 (a p38 MAPK inhibitor) and anisomycin (a p38 MAPK activator) for $30 \mathrm{~min}$.

Immunofluorescence staining. The VSMCs were cultured on sterile glass cover slips in 12-well plates. Following fixation with $4 \%$ paraformaldehyde, the VSMCs were permeabilized by $0.1 \%$ Triton $\mathrm{X}-100$ for $30 \mathrm{~min}$ at room temperature and blocked with goat serum for $1 \mathrm{~h}$ at $37^{\circ} \mathrm{C}$. The cells then covered with anti- $\alpha$-SM-actin antibody were incubated at $4^{\circ} \mathrm{C}$ in a dark humidified chamber overnight. The samples were counterstained with DAPI at room temperature for $10 \mathrm{~min}$. The images were captured using NIS-Elements imaging software (Nikon, Tokyo, Japan).

MTT assay. Cell proliferation was firstly investigated by MTT assay according to published literature (23). Briefly, the VSMCs were treated with additional $\mathrm{NaCl}$ (10-50 mM), choline chloride (10-50 $\mathrm{mM})$ or sorbital (20-100 $\mathrm{mM}$ ) in DMEM supplemented with $5 \%$ FBS for 12,24 or $48 \mathrm{~h}$. The cells were then incubated with MTT solution $(0.1 \mathrm{mg} / \mathrm{ml})$ for $4 \mathrm{~h}$. The formed formazan crystals were dissolved in $150 \mu \mathrm{l} /$ well dimethyl sulfoxide (DMSO). The absorbance was recorded at a wavelength of $490 \mathrm{~nm}$ using a microplate reader (Bio-Rad, Hercules, CA, USA). All experiments were performed at least 3 times. The relative proliferation of the cells was calculated as the absorbance of treated cells/control cells x $100 \%$.

EdU incorporation assay. Following synchronization with serum-free medium for $24 \mathrm{~h}$, the cells were treated with or without additional $\mathrm{NaCl}(30 \mathrm{mM})$ in DMEM supplemented with $5 \% \mathrm{FBS}$ for $24 \mathrm{~h}$. The EdU incorporation assay was performed according to the manufacturer's instructions (RiboBio). In brief, the VSMCs were incubated with $50 \mu \mathrm{M}$ EdU for $2 \mathrm{~h}$. Following fixation with $4 \%$ paraformaldehyde and permeabilization in $1.0 \%$ Triton X-100, the cells underwent EdU staining. The cell nuclei were counterstained with Hoechst 33342. EdU-positive nuclei were determined under a fluorescence microscope (Olympus BX51; Olympus, Tokyo, Japan). The cell 

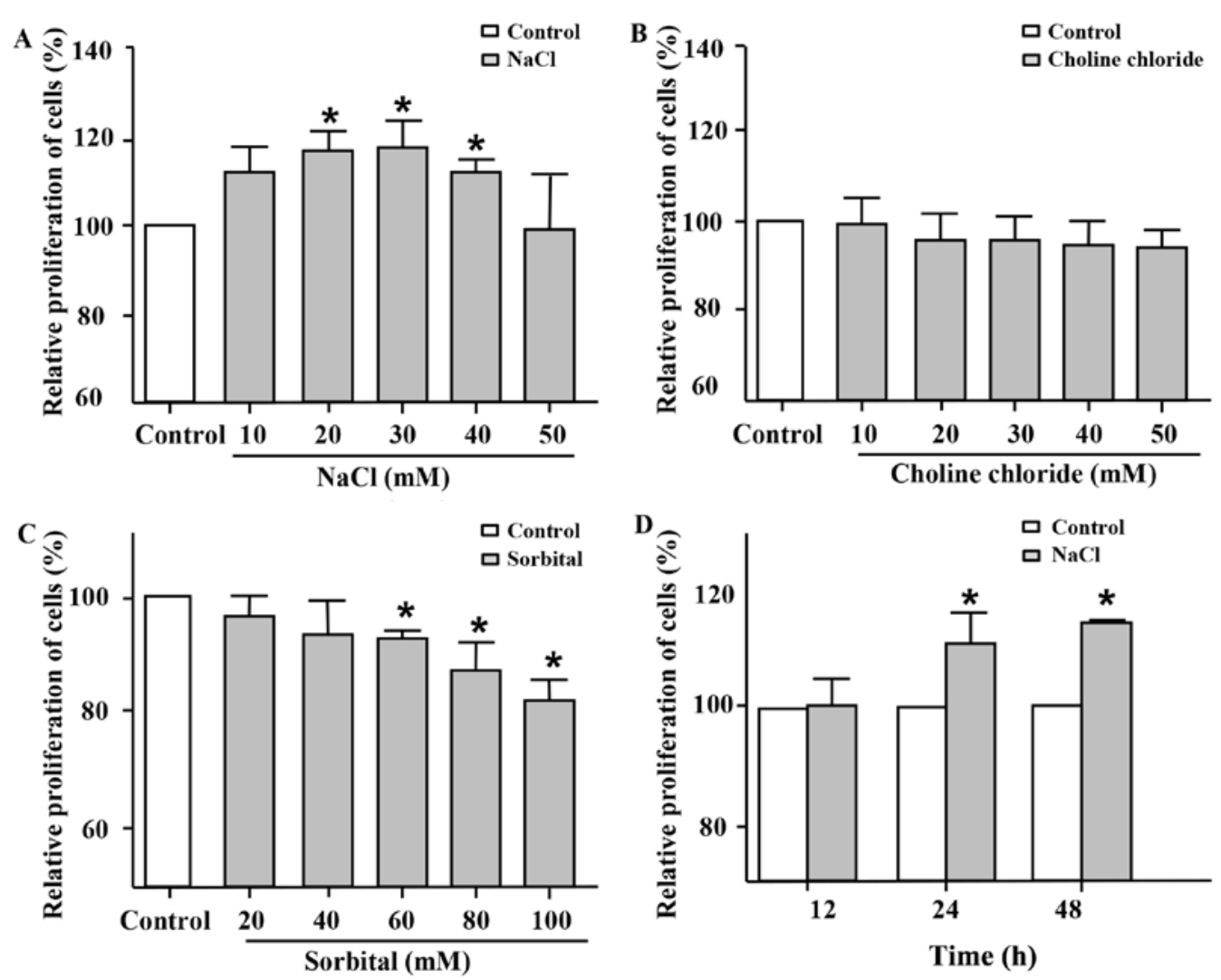

Figure 1. Effects of additional $\mathrm{NaCl}$, choline chloride and sorbital on the proliferation of vascular smooth muscle cells (VSMCs). (A-C) MTT assay for the proliferation of VSMCs following treatment with additional (A) $\mathrm{NaCl}$, (B) choline chloride and (C) sorbital for $24 \mathrm{~h}$. (D) MTT assay for the proliferation of VSMCs following treatment with or without additional $\mathrm{NaCl}(30 \mathrm{mM})$ for 12, 24 and $48 \mathrm{~h}$, respectively. Data are expressed as the means $\pm \mathrm{SD}$ from at least 3 independent experiments. ${ }^{*}<<0.05$ vs. control (untreated cells) at the same time point.

proliferation rate was calculated as the proportion of nucleated cells incorporating EdU in 5 high-power fields per well.

$R N A$ extraction and reverse transcription-quantitative polymerase chain reaction ( $R T-q P C R)$. Quantification was carried out as previously described (24). Briefly, total RNA was extracted from the cells using TRIzol reagent and reverse transcribed using the cDNA synthesis kit (Fermentas, Burlington, CA, USA). Quantitative (real-time) PCR (qPCR) was performed using SYBR ${ }^{\circledR}$ select Master Mix on an iQ5 Multicolor RealTime PCR Detection system (Bio-Rad). The primer sequences used for PCNA were as follows: sense, 5'-ACCTCACCAGC ATGTCCAA-3' and antisense, 5'-CATAGTCTGAAACTTTC TCTTGATTTG-3'. Beta-glucuronidase (GUSB) was used as a housekeeping gene and the primer sequences were: sense, 5'-CTCTGGTGGCCTTACCTGAT-3' and antisense, 5'-CAGA CTCAGGTGTTGTCA TCG-3'. The relative expression level of the target gene was then determined using a comparative method $\left(2^{-\Delta \Delta C T}\right)$.

Western blot analysis. Western blot analysis was performed as previously described (24). Briefly, the VSMCs were lysed in RIPA buffer supplemented with protease and phosphatase inhibitors. The protein content was determined using a BCA protein assay kit (Pierce, Rockford, IL, USA). Equivalent amounts of protein were subjected to $10 \%$ sodium dodecyl sulfate-polyacrylamide gel electrophoresis (SDS-PAGE) for electrophoresis and then transferred onto PVDF membranes
(Bio-Rad). The blots were incubated with primary antibodies against PCNA, p-JNK, p-ERK1/2, p-p38 MAPK and $\beta$-actin, and then with horseradish peroxidase-conjugated goat-antirabbit antibody. The protein signals were detected using chemiluminescence. All densitometric data for the target genes were corrected with $\beta$-actin as a loading control.

Statistical analysis. Data are expressed as the means \pm standard deviation (SD). Comparisons among 3 or more groups were analyzed by one-way analysis of variance (ANOVA), whereas the Student's t-test was used for comparisons between 2 groups. A value of $\mathrm{P}<0.05$ was considered to indicate a statistically significant difference. Statistical analysis was performed using SPSS 16.0 software (SPSS, Inc., Chicago, IL, USA).

\section{Results}

High sodium levels rather than high $\mathrm{Cl}^{-}$levels or osmotic pressure promote the proliferation of VSMCs. In the present study, we used $\alpha$-SM-actin as a marker of contractile VSMCs to identify the phenotype and purity of the commercially available VSMCs (25). The cultured VSMCs exhibited a spindle-like shape. Immunofluorescence staining revealed an abundance of green myonemes in the cytoplasm. The purity of the obtained cells was $>95 \%$ (data not shown).

Additional $\mathrm{NaCl}$ was added to the basal medium in order to verify whether $\mathrm{Na}^{+}$directly promotes the proliferation of VSMCs at higher concentrations. First, MTT assay was used 
A
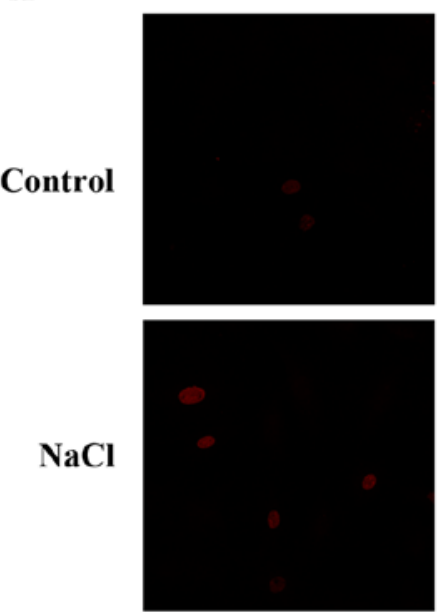

Hoechst
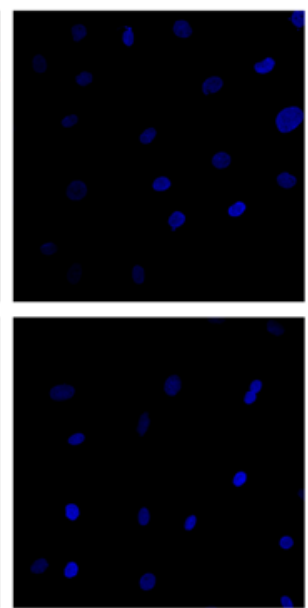

Merge

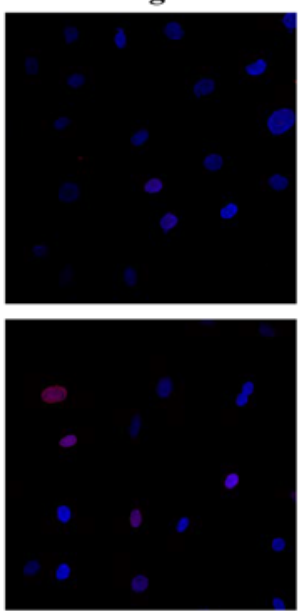

B

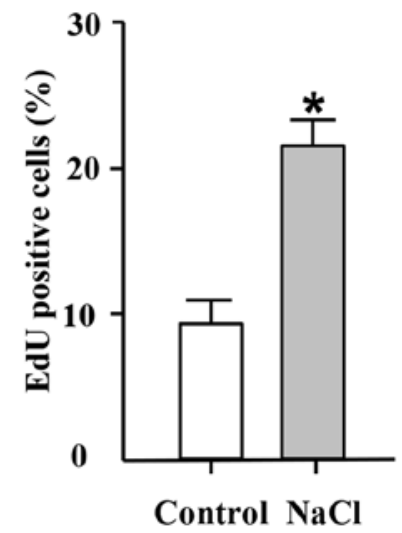

Figure 2. Effects of high sodium level on DNA synthesis. (A) 5-Ethynyl-2'-deoxyuridine (EdU) incorporation assay of vascular smooth muscle cells (VSMCs) following treatment with additional $\mathrm{NaCl}(30 \mathrm{mM})$ or not for $24 \mathrm{~h}$. Red and blue fluorescence represent EdU-positive nuclei and general nuclei, respectively (magnification, $\mathrm{x} 400$ ). (B) Quantification of the percentage of EdU-positive nuclei to total nuclei. Data are expressed as the means \pm SD from 3 independent experiments. ${ }^{*} \mathrm{P}<0.05$ vs. control (untreated cells).

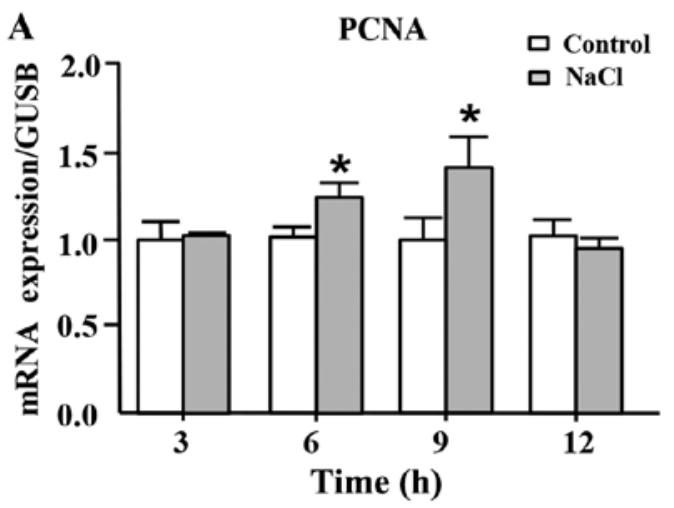

B
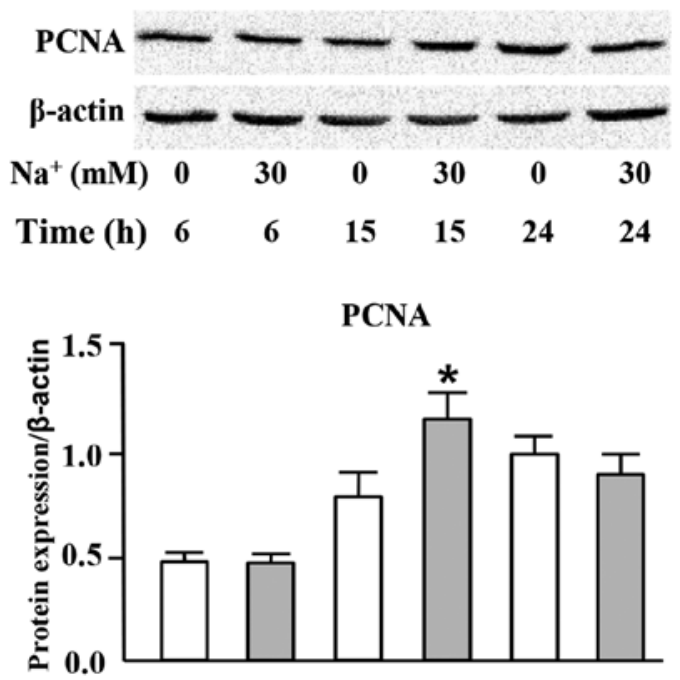

Figure 3. Expression of proliferating cell nuclear antigen (PCNA) in vascular smooth muscle cells (VSMCs). (A) PCNA expression at the mRNA level in VSMCs treated with or without additional $\mathrm{Na}^{+}(30 \mathrm{mM})$ for the indicated periods of time. Beta-glucuronidase (GUSB) was used as a loading control. (B) Western blot analysis of PCNA in cells following treatment with or without additional $\mathrm{Na}^{+}$for the indicated periods of time. $\beta$-actin was used as a loading control. Average quantification obtained by densitometric analysis of the results of western blot analysis. Data are presented as the mean \pm SD from 3 independent experiments. ${ }^{*} \mathrm{p}<0.05$ vs. control (untreated cells) at the same time point. to evaluate cell proliferation. Following incubation for $24 \mathrm{~h}$, the addition of $20-40 \mathrm{mM} \mathrm{NaCl}$ to the cell medium markedly promoted the proliferation of the VSMCs compared with the untreated control group (Fig. 1A). Furthermore, this induction of cell proliferation by the high sodium levels was the most significant when $30 \mathrm{mM} \mathrm{NaCl}$ were added. To further clarify whether the proliferative effects of $\mathrm{NaCl}$ on VSMCs are due to $\mathrm{Na}^{+}$itself, choline chloride and sorbital were also employed in the present study. Choline chloride at various concentrations, which was used as $\mathrm{Cl}^{-}$intervention, did not increase the proliferation of the VSMCs (Fig. 1B). Sorbital, which was used as osmotic intervention, exhibited no significant effect on the proliferation of the VSMCs (Fig. 1C) at low concentrations (20 and $40 \mathrm{mM}$ ). Indeed, sorbital inhibited the proliferation of the VSMCs when used at a concentration of $>60 \mathrm{mM}$. As shown in Fig. 1D, the addition of $\mathrm{NaCl}(30 \mathrm{mM}$; additional to the levels already in medium) to the cell medium promoted the proliferation of the VSMCs following incubation for 24 and $48 \mathrm{~h}$, but not for $12 \mathrm{~h}$. These results indicated that $\mathrm{Na}^{+}$at relatively high concentrations per se, rather than $\mathrm{Cl}^{-}$or osmotic pressure promoted the proliferation of VSMCs.

EdU, a thymidine analogue, is incorporated into cellular DNA during cell proliferation (26). Thus, in this study, we used the EdU incorporation assay to further confirm the effects of high sodium levels on the proliferation of VSMCs. In accordance with the results of MTT assay, EdU incorporation assay revealed that addition of $\mathrm{NaCl}(30 \mathrm{mM}$; additional to the levels already in medium) to the cell culture medium for $24 \mathrm{~h}$ increased the percentage of EdU-positive nuclei compared with the control group (Fig. 2), thus indicating an increase in DNA synthesis in the ultured VSMCs which was induced by $\mathrm{NaCl}$.

High sodium level increases PCNA expression at both the $m R N A$ and protein levels. PCNA, the eukaryotic DNA sliding clamp, confers high processivity to replicative DNA polymerase, which is recognized as a marker of cell proliferation $(27,28)$. We thus measured the mRNA and protein expression levels of PCNA in the cells cultured in medium with the addition of high 
A

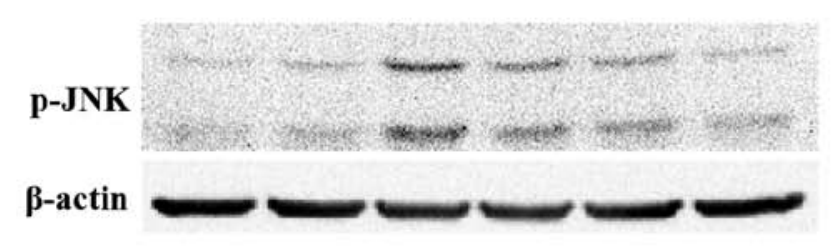

C

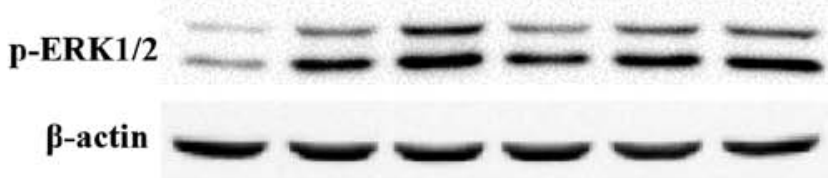

$\mathbf{E}$

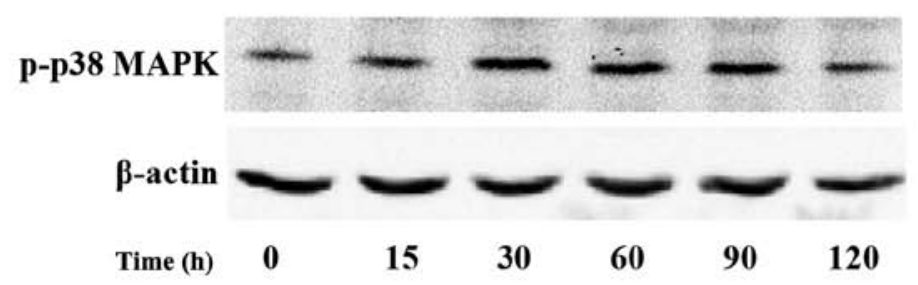

B

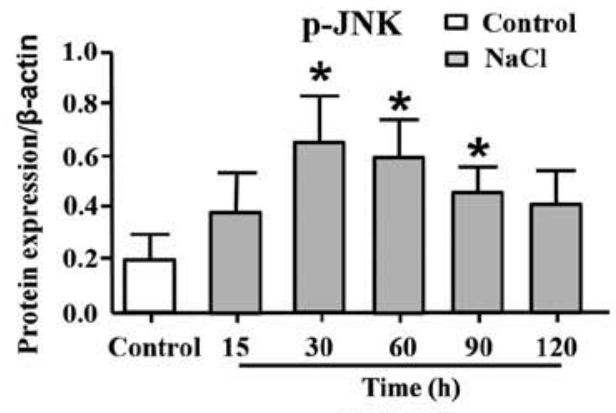

D

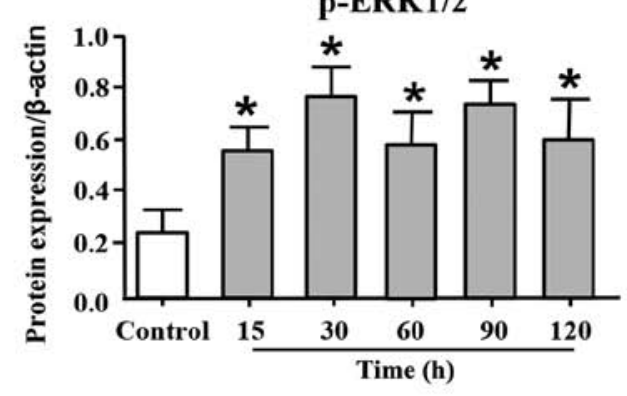

F

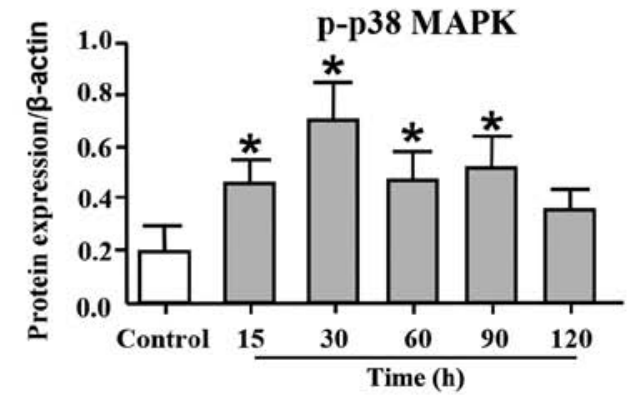

Figure 4. Expression of phosphorylated c-Jun amino N-terminal kinases (p-JNK), phosphorylated extracellular signal-regulated kinase 1/2 (p-ERK1/2) and phosphorylated p-p38 mitogen-activated protein kinase (p-p38 MAPK) in vascular smooth muscle cells (VSMCs). (A, C and E) Representive western blots of (A) p-JNK, (C) p-ERK1/2 and (E) p-p38 MAPK in VSMCs treated with or without additional $\mathrm{Na}^{+}$for the indicated periods of time. $\beta$-actin was used as a loading control. (B, D and F) Average quantification obtained by densitometric analysis of the results of western blot analysis. Data are presented as the means \pm SD from at least 3 independent experiments. " $\mathrm{P}<0.05$ vs. control (untreated cells).

level of sodium. As shown in Fig. 3A, the mRNA expression of PCNA was significantly increased following the addition of $30 \mathrm{mM} \mathrm{Na}^{+}$to the cell culture medium (additional to the levels already in medium) for 6 and $9 \mathrm{~h}$. In addition, the protein expression of PCNA was transiently, but markedly increased following the addition of $\mathrm{Na}^{+}$to the medium for $15 \mathrm{~h}$ (Fig. 3B).

High sodium level increases the phosphorylation levels of JNK, ERK1/2 and 38 MAPK. JNK, ERK1/2 and p38 MAPK are the members of MAPK family, and they play important roles in cell proliferation (29,30). Thus, in order to elucidate the underlying mechanisms responsible for the proliferative effects of additional $\mathrm{Na}^{+}$on VSMCs, we measured the phosphorylation levels of JNK, ERK1/2 and p38 MAPK by western blot analysis. As shown in Fig. 4, the expression levels of p-JNK (Fig. 4A and B), p-ERK1/2 (Fig. 4C and D) and p-p38 MAPK (Fig. 4E and F) were significantly increased following the addition of $30 \mathrm{mM} \mathrm{Na}^{+}$to the cell culture medium (additional to the levels already in medium) for $30 \mathrm{~min}$, and such an increase was maintained until $120 \mathrm{~min}$ post-treatment.

High sodium level increases PCNA expression at the protein level through the JNK/ERK1/2 pathway. To further investi- gate the exact roles of MAPK members in the high-sodium induced proliferation of VSMCs, specific inhibitors of JNK and ERK1/2 were used in this study. As shown in Fig. 5, both SP600125, a JNK inhibitor (Fig. 5A), and PD98059, an ERK1/2 inhibitor (Fig. 5B), almost completely inhibited PCNA expression induced by the addition of $\mathrm{Na}^{+}(30 \mathrm{mM}$; additional to the levels already in medium). The JNK inhibitor, SP600125, also decreased the expression of $\mathrm{p}$-ERK $1 / 2$ which was induced by the addition of $\mathrm{Na}^{+}(30 \mathrm{mM}$; additional to the levels already in medium) (Fig. 5C). However, the ERK1/2 inhibitor, PD98059, did not significantly affect the phosphorylation level of JNK (Fig. 5D). These results indicated that high sodium levels induced the expression of PCNA through JNK/ERK1/2 pathway, and that JNK was located upstream of ERK1/2.

High sodium level simultaneously inhibits PCNA expression through p38 MAPK. In the present study, we also used SB203580 (a p38 MAPK inhibitor) in order to examine the role of p38 MAPK in the high-sodium induced proliferation of VSMCs. Surprisingly, SB203580 markedly increased PCNA expression at the protein level (Fig. 6A). Conversely, anisomycin, the activator of p38 MAPK, inhibited PCNA expression (Fig. 6B). These results suggested that activated 
A
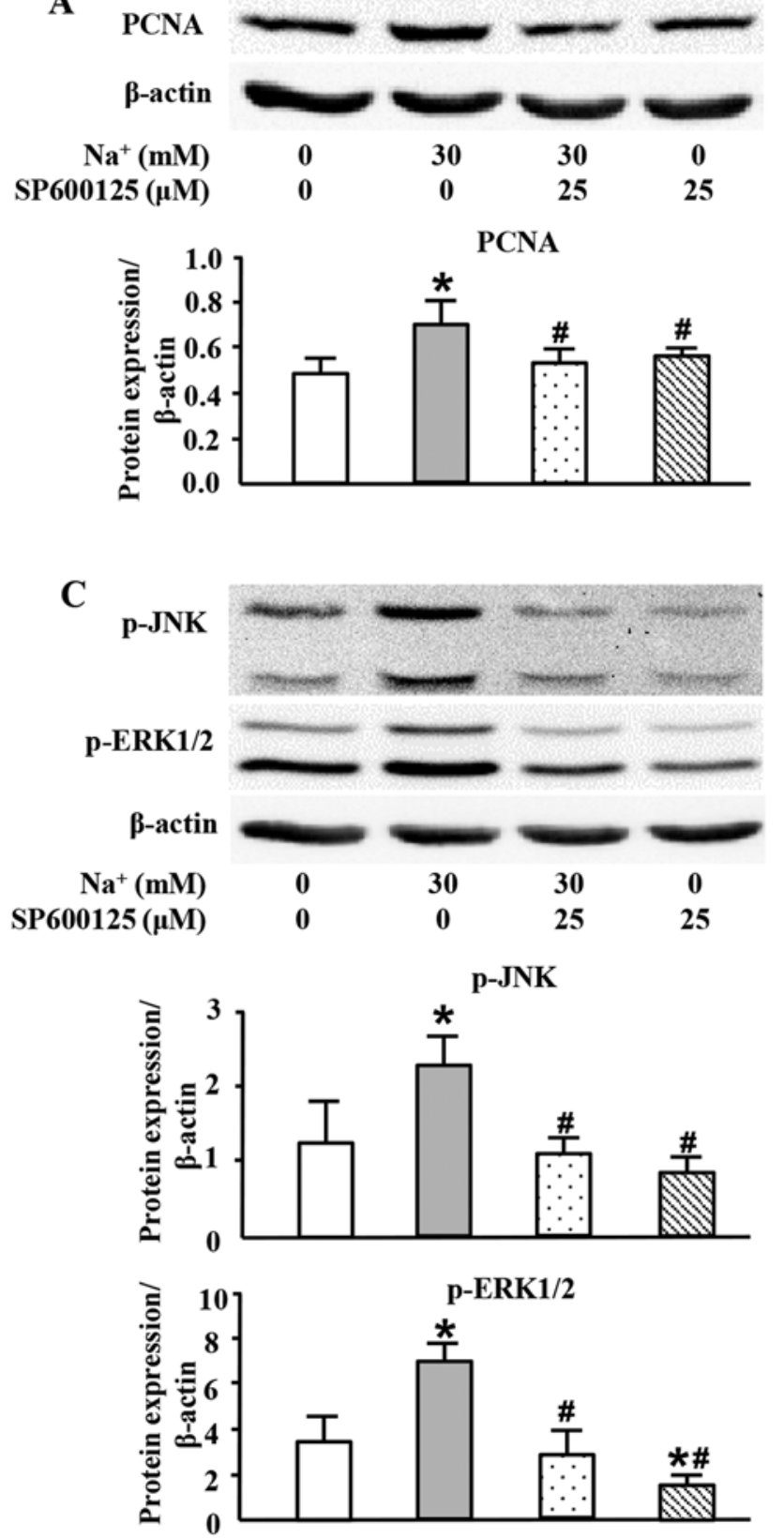

B
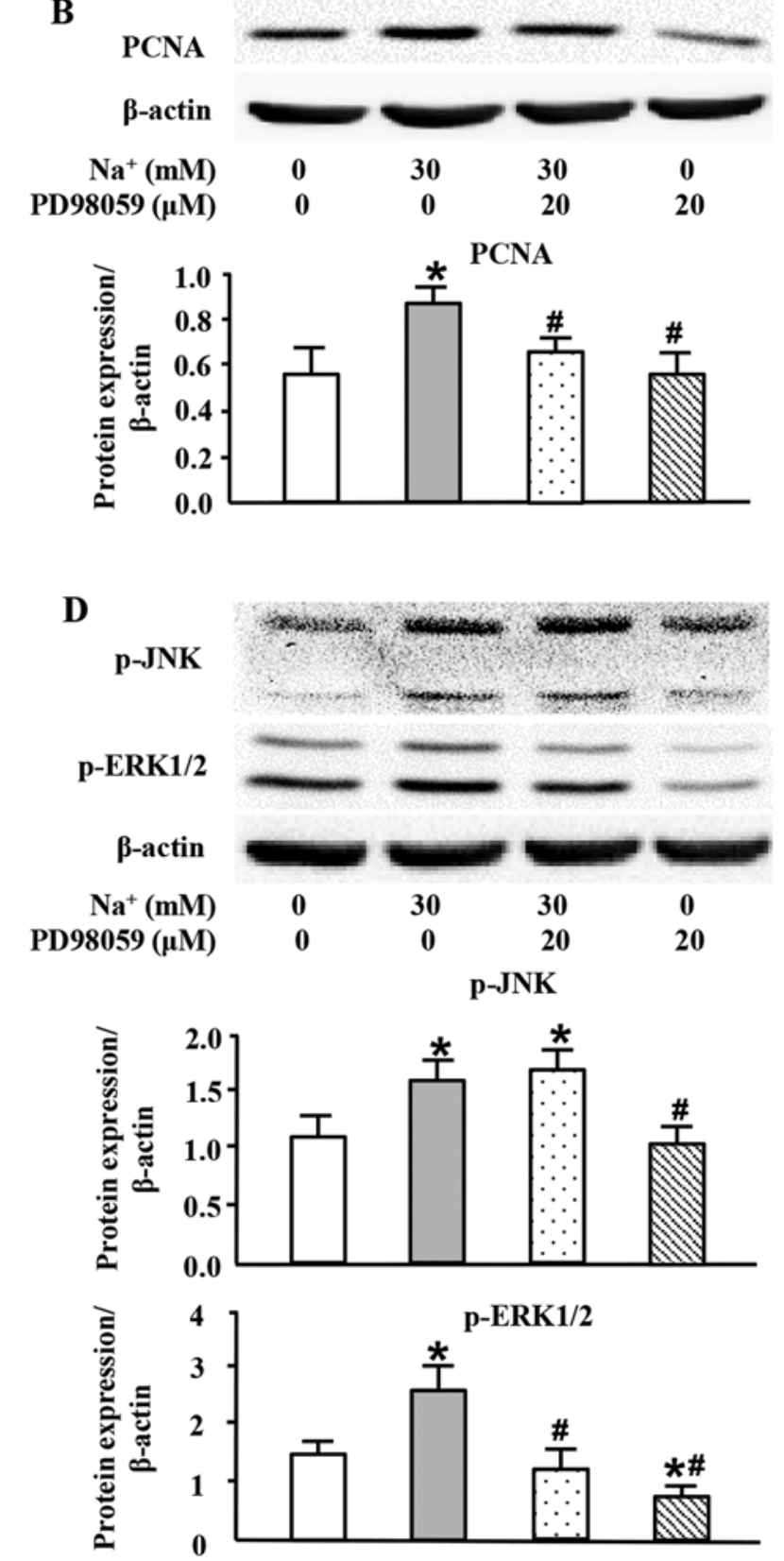

Figure 5. Roles of phosphorylated c-Jun amino N-terminal kinases (p-JNK) and phosphorylated extracellular signal-regulated kinase 1/2 (p-ERK1/2) in the proliferation of vascular smooth muscle cells (VSMCs) induced by high sodium. (A and B) Western blot analysis of proliferating cell nuclear antigen (PCNA) in VSMCs treated with (A) SP600125 (a JNK inhibitor), (B) PD980591 (an ERK1/2 inhibitor) for 30 min prior to exposure to additional Na $\mathrm{Na}^{+}(30 \mathrm{mM})$ for a further $15 \mathrm{~h}$. (C and D) Western blot analysis of p-JNK and p-ERK in VSMCs treated with (C) SP600125 and (D) PD980591 for 30 min prior to exposure to additional $\mathrm{Na}^{+}(30 \mathrm{mM})$ for a further $30 \mathrm{~min}$. $\beta$-actin was used as a loading control. Average quantification obtained by densitometric analysis of the results of western blot analysis. Data are presented as the means $\pm \mathrm{SD}$ from 3 independent experiments. ${ }^{\mathrm{P}} \mathrm{P}<0.05$ vs. control (untreated cells); ${ }^{~} \mathrm{P}<0.05$ vs. cells treated with $\mathrm{NaCl}$ alone.

p38 MAPK played an opposite role to JNK and ERK1/2 in the high-sodium induced proliferation of VSMCs.

\section{Discussion}

As the major risk factor for cardiovascular diseases (1-4,31), increasing attention has been paid to the physiological and pathophysiological effects of excess $\mathrm{Na}^{+}$consumption. The present study demonstrated two major findings: i) Additional $\mathrm{Na}^{+}$per se increased the proliferation of VSMCs weakly (10\%), but directly at relatively higher concentrations; ii) the addition of $\mathrm{Na}^{+}$activated the JNK/ERK1/2/PCNA pathway to promote the proliferation of VSMCs, and this abnormal proliferative effect was limited by simultaneously activated p38 MAPK.

In the present study, we mainly focused on the direct effects of additional $\mathrm{NaCl}$ on the proliferation of VSMCs to avoid the confounding impact from other factors, as shown in in vivo studies, such as RAAS $(20,21)$, endothelial function (22) and ouabain (32). We demonstrated that additional $\mathrm{Na}^{+}$itself directly increased the proliferation of VSMCs at a concentration ranging from 20 to $40 \mathrm{mM}$ (Figs. 1-3). Since the basic culture medium of VSMCs is DMEM, in which the $\mathrm{Na}^{+}$concentration 
A

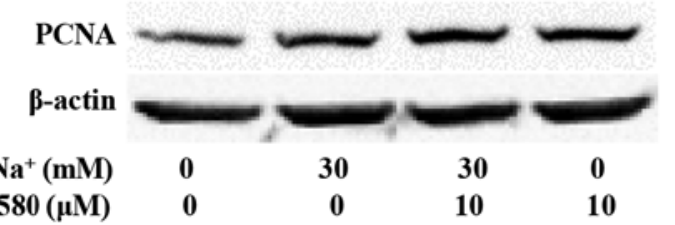

B
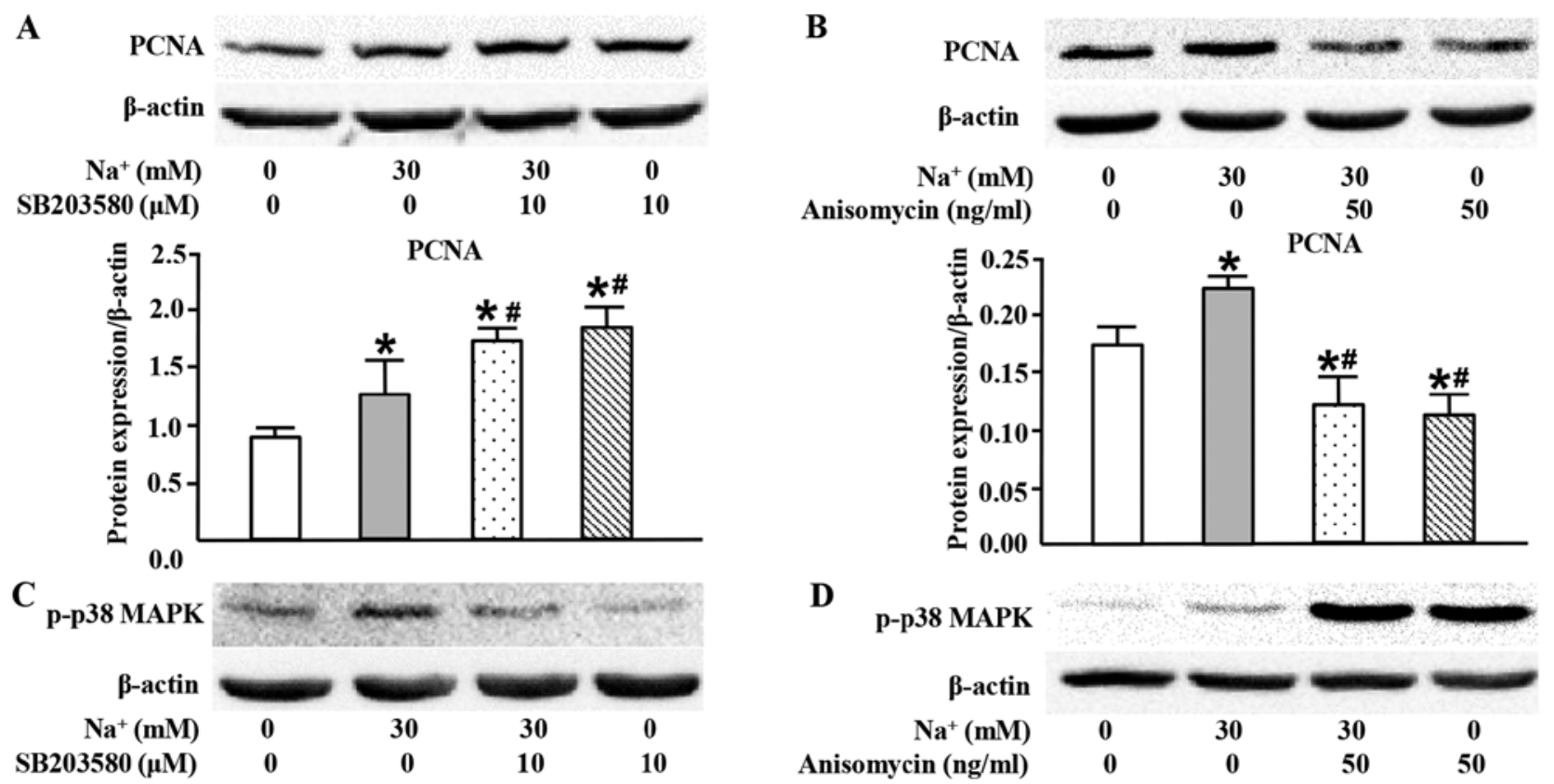

Figure 6. Role of phosphorylated p38 mitogen-activated protein kinase (p-p38 MAPK) in the proliferation of vascular smooth muscle cells (VSMCs) induced by high sodium. (A and B) Western blot analysis of proliferating cell nuclear antigen (PCNA) in VSMCs treated with (A) SB203580 (a p38 MAPK inhibitor) and (B) anisomycin (a p38 MAPK activator) for 30 min prior to exposure to additional $\mathrm{Na}^{+}(30 \mathrm{mM})$ for a further $15 \mathrm{~h}$. Average quantification obtained by densitometric analysis of the results of western blot analysis. Data are presented as the means \pm SD from 3 independent experiments. ${ }^{*}<0.05$ vs. control (untreated cells); ${ }^{\text {P }}<0.05$ vs. cells treated with $\mathrm{NaCl}$ alone. (C and D) Representative western blots of p-p38 MAPK in VSMCs treated with (C) p38 SB203580 and (D) anisomycin for $30 \mathrm{~min}$ prior to exposure to additional $\mathrm{Na}^{+}(30 \mathrm{mM})$ for a further $30 \mathrm{~min}$. $\beta$-actin was used as a loading control.

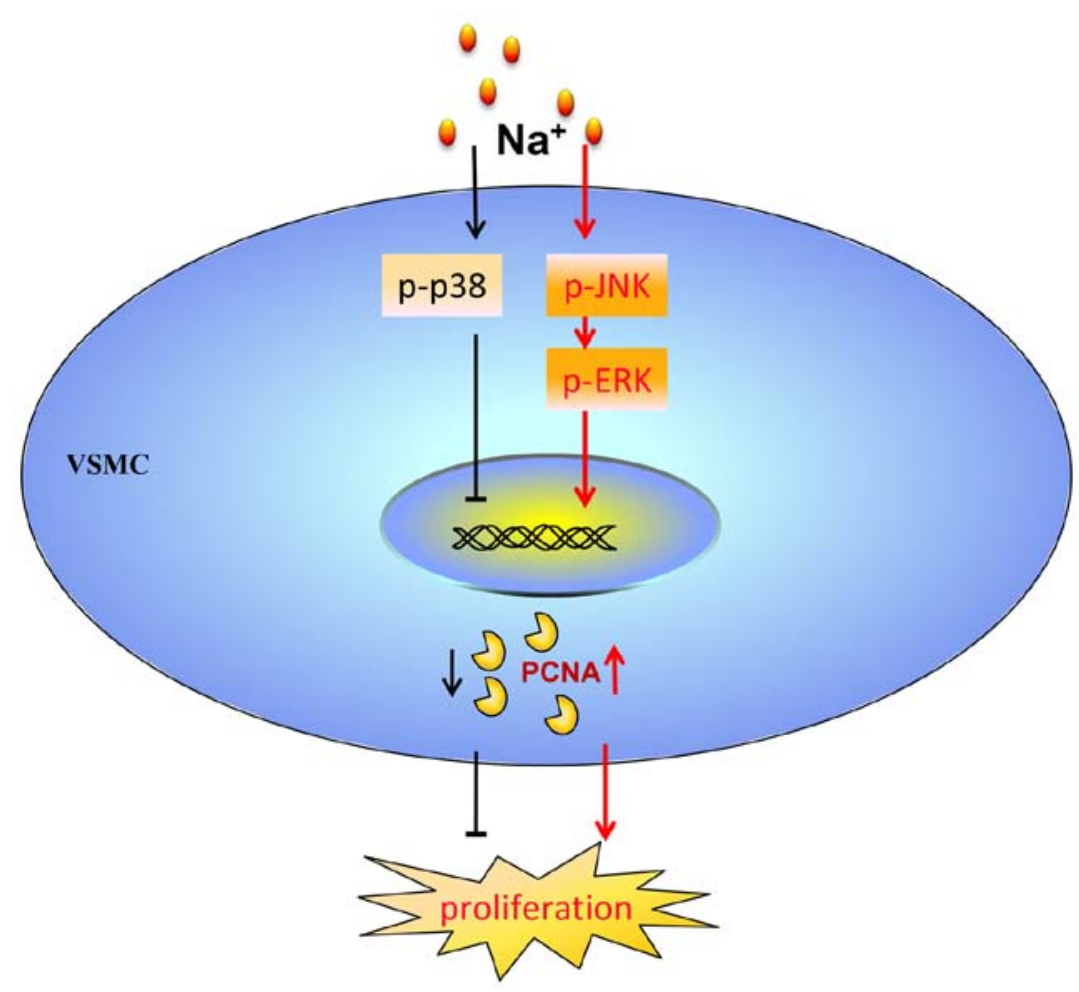

Figure 7. Schematic diagram of the mechanisms through which high sodium levels increase the proliferation of vascular smooth muscle cells (VSMCs).

is approximately $156 \mathrm{mM}$, the final $\mathrm{Na}^{+}$concentrations thus ranged from 176 to $196 \mathrm{mM}$ in the present study. This level of $\mathrm{Na}^{+}$concentration could appear both in the renal medulla under physiological conditions (5) and in the skin interstitium due to HSD (10). Although $\mathrm{Na}^{+}$increased the proliferation of VSMCs by only approximately $10 \%$ compared with the control group, and this effect is not as prominent as that of other factors, such as angiotensin II (20), its proliferative effects were still significant since i) the proliferation of the VSMCs was maintained at a low level when the cells were exposed to relatively higher 
concentrations of $\mathrm{Na}^{+}$. This interesting response of VSMCs to high concentrations of $\mathrm{Na}^{+}$may indicate a possible mechanism which plays a role in the adaptation of tissues exposed to fluctuant concentrations of $\mathrm{Na}^{+}$in the renal medulla; ii) aside from the increase in blood pressure, the activation of RAAS and endothelial dysfunction, the increase in the proliferation of the VSMCs by $10 \%$ induced by the interstitial $\mathrm{Na}^{+}$accumulation itself can still be considered as an important pathogenic factor for hypertension, cardiovascular disease and stroke; iii) as previously described by Singer et al (16), medication against RAAS and other possible treatments cannot solve all the health issues and sodium restriction itself is a simple, but significant prevention or even therapeutic approach.

As an extracellular stimuli, it has been proven that $\mathrm{NaCl}$ can affect MAPKs in several cell types, such as endothelial cells (33), monocytes (34) and HEK293 cells (35). For cell cycle progression, it is considered that the activation of JNK and ERK1/2 can accelerate cell proliferation $(36,37)$, whereas p38 MAPK plays an opposite role (38-40). In the present study, $\mathrm{Na}^{+}$increased the phosphorylation of JNK (Fig. 4A) and ERK1/2 (Fig. 4C) and increased PCNA expression (Fig. 5), and these results were consistent with those of the above-mentioned studies. Moreover, p38 MAPK was phosphorylated (Fig. 4E) at the same time, but played an opposite role (Fig. 6). Since $\mathrm{Na}^{+}$ is an essential nutrient for normal cell function, the findings of our study indicate that high sodium levels may simultaneously activate $\mathrm{p} 38 \mathrm{MAPK}$, a negative regulatory mechanism, in order to limit abnormal proliferation, maintaining cell proliferation at a relatively low level.

There were several limitations to the present study as follows: i) in spite of the abundance of existing connective tissue, to the best of our knowledge, no studies to date have demonstrated the exact amount of $\mathrm{Na}^{+}$which is accumulated in the vascular wall. Therefore, it is necessary to develop a novel, but feasible method with which to determine the accumulation of $\mathrm{Na}^{+}$and measure its exact concentrations in the vascular walls due to HSD; ii) the detailed mechanisms and the crosstalk between JNK, ERK1/2 and p38 MAPK warrants further investigations.

In conclusion, the findings of this study demonstrated that additional $\mathrm{Na}^{+}$per se directly promoted the proliferation of VSMCs through the JNK/ERK1/2/PCNA pathway. At the same time, the proliferation of the VSMCs which was induced by additional $\mathrm{Na}^{+}$was maintained at a low level via the activation of p38 MAPK (Fig. 7).

\section{Acknowledgements}

This study was financially supported by the National Natural Science Fund (nos.91339116 and 81102843) and the National Basic Research Program of China ('973 Project' no. 2012CB517804).

\section{References}

1. Aburto NJ, Ziolkovska A, Hooper L, Elliott P, Cappuccio FP and Meerpohl JJ: Effect of lower sodium intake on health: Systematic review and meta-analyses. BMJ 346: f1326, 2013.

2. Graudal NA, Hubeck-Graudal T and Jürgens G: Effects of low-sodium diet vs. high-sodium diet on blood pressure, renin, aldosterone, catecholamines, cholesterol, and triglyceride (Cochrane Review). Am J Hypertens 25: 1-15, 2012.
3. He FJ, Li J and Macgregor GA: Effect of longer term modest salt reduction on blood pressure: Cochrane systematic review and meta-analysis of randomised trials. BMJ 346: f1325, 2013.

4. Taylor RS, Ashton KE, Moxham T, Hooper L and Ebrahim S: Reduced dietary salt for the prevention of cardiovascular disease: A meta-analysis of randomized controlled trials (Cochrane review). Am J Hypertens 24: 843-853, 2011.

5. Neuhofer W and Beck FX: Cell survival in the hostile environment of the renal medulla. Annu Rev Physiol 67: 531-555, 2005.

6. Cha JH, Woo SK, Han KH, Kim YH, Handler JS, Kim J and Kwon HM: Hydration status affects nuclear distribution of transcription factor tonicity responsive enhancer binding protein in rat kidney. J Am Soc Nephrol 12: 2221-2230, 2001

7. Kültz D and Chakravarty D: Hyperosmolality in the form of elevated $\mathrm{NaCl}$ but not urea causes DNA damage in murine kidney cells. Proc Natl Acad Sci USA 98: 1999-2004, 2001.

8. Zhang Z, Dmitrieva NI, Park JH, Levine RL and Burg MB: High urea and $\mathrm{NaCl}$ carbonylate proteins in renal cells in culture and in vivo, and high urea causes 8-oxoguanine lesions in their DNA. Proc Natl Acad Sci USA 101: 9491-9496, 2004.

9. Santos BC, Chevaile A, Hébert MJ, Zagajeski J and Gullans SR: A combination of $\mathrm{NaCl}$ and urea enhances survival of IMCD cells to hyperosmolality. Am J Physiol 274: F1167-F1173, 1998.

10. Machnik A, Neuhofer W, Jantsch J, Dahlmann A, Tammela T, Machura K, Park JK, Beck FX, Müller DN, Derer W, et al: Macrophages regulate salt-dependent volume and blood pressure by a vascular endothelial growth factor-C-dependent buffering mechanism. Nat Med 15: 545-552, 2009.

11. Nijst P, Verbrugge FH, Grieten L, Dupont M, Steels P, Tang WH and Mullens W: The pathophysiological role of interstitial sodium in heart failure. J Am Coll Cardiol 65: 378-388, 2015

12. Heer M, Baisch F, Kropp J, Gerzer R and Drummer C: High dietary sodium chloride consumption may not induce body fluid retention in humans. Am J Physiol Renal Physiol 278: F585-F595, 2000.

13. Kirkendall AM, Connor WE, Abboud F, Rastogi SP, Anderson TA and Fry M: The effect of dietary sodium chloride on blood pressure, body fluids, electrolytes, renal function, and serum lipids of normotensive man. J Lab Clin Med 87: 411-434, 1976.

14. Palacios C, Wigertz K, Martin BR, Jackman L, Pratt JH, Peacock M, McCabe G and Weaver CM: Sodium retention in black and white female adolescents in response to salt intake. J Clin Endocrinol Metab 89: 1858-1863, 2004.

15. Titze J, Shakibaei M, Schafflhuber M, Schulze-Tanzil G, Porst M, Schwind KH, Dietsch P and Hilgers KF: Glycosaminoglycan polymerization may enable osmotically inactive $\mathrm{Na}^{+}$storage in the skin. Am J Physiol Heart Circ Physiol 287: H203-H208, 2004.

16. Singer DR, Markandu ND, Sugden AL, Miller MA and MacGregor GA: Sodium restriction in hypertensive patients treated with a converting enzyme inhibitor and a thiazide. Hypertension 17: 798-803, 1991.

17. Matsushita N, Kitazato KT, Tada Y, Sumiyoshi M, Shimada K, Yagi K, Kanematsu Y, Satomi J and Nagahiro S: Increase in body $\mathrm{Na}^{+} /$water ratio is associated with cerebral aneurysm formation in oophorectomized rats. Hypertension 60: 1309-1315, 2012.

18. Lacolley P, Regnault V, Nicoletti A, Li Z and Michel JB: The vascular smooth muscle cell in arterial pathology: A cell that can take on multiple roles. Cardiovasc Res 95: 194-204, 2012.

19. Shi N and Chen SY: Mechanisms simultaneously regulate smooth muscle proliferation and differentiation. J Biomed Res 28: 40-46, 2014.

20. Liu G, Hitomi H, Rahman A, Nakano D, Mori H, Masaki T, Ma H, Iwamoto T, Kobori $\mathrm{H}$ and Nishiyama A: High sodium augments angiotensin II-induced vascular smooth muscle cell proliferation through the ERK1/2-dependent pathway. Hypertens Res 37: 13-18, 2014

21. Makita S, Nakamura M, Yoshida $H$ and Hiramori K: Effect of angiotensin II receptor blocker on angiotensin II stimulated DNA synthesis of cultured human aortic smooth muscle cells. Life Sci 56: PL383-PL388, 1995.

22. Komuro I, Kurihara H, Sugiyama T, Yoshizumi M, Takaku F and Yazaki Y: Endothelin stimulates c-fos and c-myc expression and proliferation of vascular smooth muscle cells. FEBS Lett 238: 249-252, 1988.

23. Liu J, Ren Y, Kang L and Zhang L: Oxidized low-density lipoprotein increases the proliferation and migration of human coronary artery smooth muscle cells through the upregulation of osteopontin. Int J Mol Med 33: 1341-1347, 2014. 
24. Wang H, Liu Y, Zhu L, Wang W, Wan Z, Chen F, Wu Y, Zhou J and Yuan Z: 17ß-estradiol promotes cholesterol efflux from vascular smooth muscle cells through a liver $\mathrm{X}$ receptor $\alpha$-dependent pathway. Int J Mol Med 33: 550-558, 2014.

25. Weissberg PL, Cary NR and Shanahan CM: Gene expression and vascular smooth muscle cell phenotype. Blood Press Suppl 2: 68-73, 1995.

26. Salic A and Mitchison TJ: A chemical method for fast and sensitive detection of DNA synthesis in vivo. Proc Natl Acad Sci USA 105: 2415-2420, 2008.

27. Guzińska-Ustymowicz K, Pryczynicz A, Kemona A and Czyzewska J: Correlation between proliferation markers: PCNA, $\mathrm{Ki}-67, \mathrm{MCM}-2$ and antiapoptotic protein $\mathrm{Bcl}-2$ in colorectal cancer. Anticancer Res 29: 3049-3052, 2009.

28. Liu D, Huang Y, Bu D, Liu AD, Holmberg L, Jia Y, Tang C, $\mathrm{Du} \mathrm{J}$ and Jin H: Sulfur dioxide inhibits vascular smooth muscle cell proliferation via suppressing the Erk/MAP kinase pathway mediated by cAMP/PKA signaling. Cell Death Dis 5: e1251, 2014.

29. Boutros T, Chevet E and Metrakos P: Mitogen-activated protein (MAP) kinase/MAP kinase phosphatase regulation: Roles in cell growth, death, and cancer. Pharmacol Rev 60: 261-310, 2008.

30. Cargnello $M$ and Roux PP: Activation and function of the MAPKs and their substrates, the MAPK-activated protein kinases. Microbiol Mol Biol Rev 75: 50-83, 2011.

31. Powles J, Fahimi S, Micha R, Khatibzadeh S, Shi P, Ezzati M, Engell RE, Lim SS, Danaei G, Mozaffarian D, et al; Global Burden of Diseases Nutrition and Chronic Diseases Expert Group (NutriCoDE): Global, regional and national sodium intakes in 1990 and 2010: A systematic analysis of $24 \mathrm{~h}$ urinary sodium excretion and dietary surveys worldwide. BMJ Open 3 : e003733, 2013

32. Blaustein MP, Leenen FHH, Chen L, Golovina VA, Hamlyn JM, Pallone TL, Van Huysse JW, Zhang J and Wier WG: How NaCl raises blood pressure: A new paradigm for the pathogenesis of salt-dependent hypertension. Am J Physiol Heart Circ Physiol 302: H1031-H1049, 2012.
33. Duzgun SA, Rasque H, Kito H, Azuma N, Li W, Basson MD, Gahtan V, Dudrick SJ and Sumpio BE: Mitogen-activated protein phosphorylation in endothelial cells exposed to hyperosmolar conditions. J Cell Biochem 76: 567-571, 2000.

34. Kleinewietfeld M, Manzel A, Titze J, Kvakan H, Yosef N, Linker RA, Muller DN and Hafler DA: Sodium chloride drives autoimmune disease by the induction of pathogenic TH17 cells. Nature 496: 518-522, 2013.

35. Zhou X, Ferraris JD, Dmitrieva NI, Liu Y and Burg MB: MKP-1 inhibits high NaCl-induced activation of $\mathrm{p} 38$ but does not inhibit the activation of TonEBP/OREBP: Opposite roles of p38alpha and p38delta. Proc Natl Acad Sci USA 105: 5620-5625, 2008.

36. Jaeschke A, Karasarides M, Ventura JJ, Ehrhardt A, Zhang C, Flavell RA, Shokat KM and Davis RJ: JNK2 is a positive regulator of the cJun transcription factor. Mol Cell 23: 899-911, 2006.

37. Meloche S and Pouysségur J: The ERK1/2 mitogen-activated protein kinase pathway as a master regulator of the G1- to S-phase transition. Oncogene 26: 3227-3239, 2007.

38. Cuadrado A and Nebreda AR: Mechanisms and functions of p38 MAPK signalling. Biochem J 429: 403-417, 2010.

39. Mikhailov A, Shinohara M and Rieder CL: The p38-mediated stress-activated checkpoint. A rapid response system for delaying progression through antephase and entry into mitosis. Cell Cycle 4: 57-62, 2005.

40. Perdiguero E, Ruiz-Bonilla V, Serrano AL and MuñozCánoves P: Genetic deficiency of p38alpha reveals its critical role in myoblast cell cycle exit: The p38alpha-JNK connection. Cell Cycle 6: 1298-1303, 2007. 